\title{
Plasma sheet fast flows and auroral dynamics during substorm: a case study
}

\author{
N. L. Borodkova ${ }^{1}$, A. G. Yahnin ${ }^{2}$, K. Liou ${ }^{3}$, J.-A. Sauvaud ${ }^{4}$, A. O. Fedorov ${ }^{4}{ }^{*}$, V. N. Lutsenko ${ }^{1}$, M. N. Nozdrachev ${ }^{1}$, \\ and A. A. Lyubchich ${ }^{2}$ \\ ${ }^{1}$ Space Research Institute, Russian Academy of Sciences, Moscow, Russia \\ ${ }^{2}$ Polar Geophysical Institute, Apatity, Russia \\ ${ }^{3}$ Applied Physics Laboratory, Johns Hopkins University, Laurel, USA \\ ${ }^{4}$ Centre d'Etude Spatiale des Rayonnements, Toulouse, France \\ *On leave from the Space Research Institute, Moscow
}

Received: 16 May 2001 - Revised: 5 November 2001 - Accepted: 11 December 2001

\begin{abstract}
Interball-1 observations of a substorm development in the mid-tail on 16 December 1998 are compared with the auroral dynamics obtained from the Polar UV imager. Using these data, the relationship between plasma flow directions in the tail and the location of the auroral activation is examined. Main attention is given to tailward and earthward plasma flows, interpreted as signatures of a Near Earth Neutral Line (NENL). It is unambiguously shown that in the mid-plasma sheet the flows were directed tailward when the auroral bulge developed equatorward of the spacecraft ionospheric footprint. On the contrary, when active auroras moved poleward of the Interball-1 projection, earthward fast flow bursts were observed. This confirms the concept that the NENL (or flow reversal region) is the source of auroras forming the poleward edge of the auroral bulge. The observed earthward flow bursts have all typical signatures of Bursty Bulk Flows (BBFs), described by Angelopolous et al. (1992). These BBFs are related to substorm activations starting at the poleward edge of the expanded auroral bulge. We interpret the BBFs as a result of reconnection pulses occurring tailward of Interball-1. In addition, some non-typically observed phenomena were detected in the plasma sheet during this substorm: (i) tailward/earthward flows were superimposed on a very strong duskward flow, and (ii) wavy structures of both magnetic field and plasma density were registered. The latter observation is probably linked to the filamentary structure of the current sheet.
\end{abstract}

Key words. Magnetospheric physics (auroral phenomena; plasma sheet; storms and substorms)

\section{Introduction}

Magnetospheric substorms represent one of the basic forms of interaction between the solar wind and magnetosphere, and as such are intensively studied. It seems that the most fully developed model of substorm is the Near Earth Neutral

Correspondence to: J.-A. Sauvaud (sauvaud@cesr.cnes.fr)
Line (NENL) model (e.g. Baker et al., 1996), which provides an explanation for most of the substorm related mesoand large-scale phenomena. In particular, according to this model, the reconnection which occurs at the NENL produces in the plasma sheet the tailward and earthward plasma flows typically observed in situ during substorms and at times, simultaneously observed by radial-spaced spacecraft (e.g. Petrukovich et al., 1998). The NENL appears at the substorm onset (e.g. Nagai et al., 1998), and in the course of the expansion phase, it shifts/reappears further down the tail (Hones, 1979; Angelopolous et al., 1996). The fast tailward retreat of the NENL is associated with the poleward shift of auroras forming the auroral bulge (Hones, 1992). Several authors suggest that the NENL is directly related to the poleward edge of active auroras (e.g. Pudovkin et al., 1991).

Many past and recent studies indicated that in the midtail, fast tailward flows occur at substorm onsets (e.g. Hones, 1979; Nagai et al., 1998) in association with auroral brightenings (e.g. Ieda et al., 2001).

Angelopolous et al. (1992) described a phenomenon called Bursty Bulk Flows (BBFs) occurring in the central plasma sheet, and related to earthward plasma transport. It has been suggested (Henderson et al., 1998; Sergeev et al., 1999, 2000; Solovyev et al., 1999) that BBFs relate to the northsouth auroral forms, which often occur within the auroral bulge during expansion and recovery phases of substorm (e.g. Nakamura et al., 1993; Henderson et al., 1994). A close relationship between BBFs, north-south auroral structures moving equatorward, and intensifications at the poleward boundary of the auroral display has been demonstrated by Zesta et al. (2000) from correlated observations in the midtail and on the ground. Using the mid-tail plasma data and simultaneous global auroral images, Nakamura et al. (2000) showed that flow bursts are closely associated with auroral brightenings at the poleward edge of the auroral oval and with small substorm/pseudo-breakup activations. Fairfield et al. (1999) have also demonstrated that fast earthward plasma sheet flows detected at distances $<15 R_{E}$ are related to the appearance of the auroral expanding bulge. 
a)

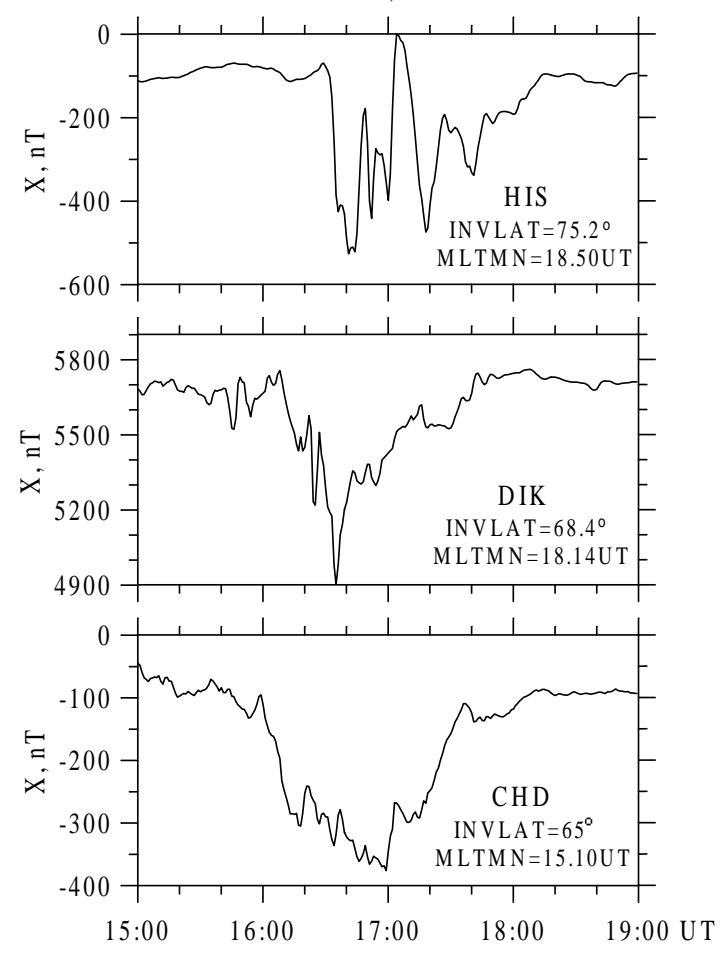

b)
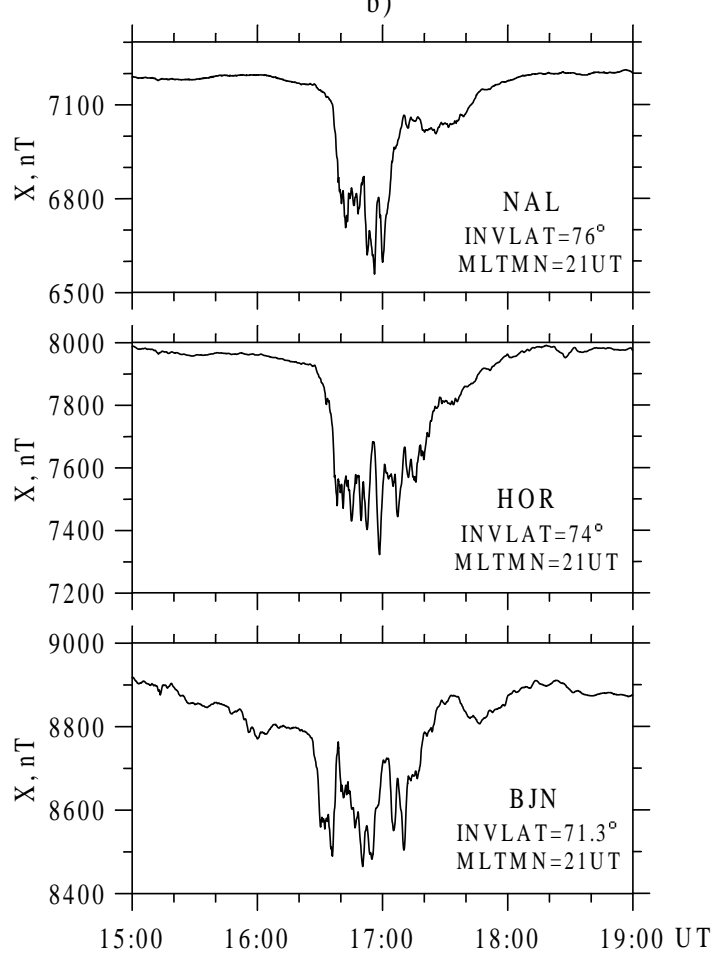

Fig. 1. (a) $X$-component of the ground magnetic field from Siberia and (b) from Scandinavia for 15:00-19:00 UT on 16 December 1998.

Timing of the fast flows relative to substorm phase and to the location of auroral brightenings is essential in order to test the different substorm models. In this study we will analyze the relationship between the flow direction in the tail and the auroral dynamics during a moderate substorm that occurred in the time interval 15:00-18:00 UT on 16 December 1998. The results will be interpreted on the basis of the NENL model.

\section{Data sources}

For this study we used the plasma and magnetic field measurements taken on board the Interball-1 satellite located at mid-tail at $X_{\mathrm{gsm}}=-24.8 R_{E}, Y_{\mathrm{gsm}}=10.7 R_{E}, Z_{\mathrm{gsm}}=$ $-3.4 R_{E}$. Images from the Polar UVI instrument provided the auroral dynamics. In order to achieve a better time resolution ( $\sim 1-2 \mathrm{~min})$, the images in both LBHL and LBHS spectral lines were used. Magnetometer data from several ground stations in Siberia, Kola Peninsula, and Scandinavia were also used for this substorm analysis.

Interplanetary conditions were monitored by the WIND spacecraft located close to the Earth at $X_{\mathrm{gsm}}=9 R_{E}, Y_{\mathrm{gsm}}=$ $-33 R_{E}$, and $Z_{\mathrm{gsm}}=22 R_{E}$. WIND data indicate that the substorm event discussed here was initiated by a southward turning of the IMF. The solar wind dynamic pressure remained stable and equal to $1.0-1.5 \mathrm{nPa}$, during the event (data not shown).

\section{Ground observations}

The event presented here follows an interval of relative quietness. Near 16:00 UT, a negative bay of the $X$-component of the magnetic field was registered in the night sector, as evidenced from Fig. 1a, which displays magnetograms from Chokurdakh, Dixon and Heiss Island. Chokurdakh was located at magnetic midnight, while Dixon and Bear Island were located in the evening sector. There was a continuous Pi2-like pulsation activity registered in the night and evening sectors (Yakutsk, Irkutsk, Lovozero, Sodankyla). The substorm onset at $\sim 16: 00$ UT was associated with a the sharp increase in the pulsation amplitude (data not shown). Until $\sim$ 16:30 UT, magnetic bays were not observed in the evening sector, but after that time, a negative excursion of the $X$ component of the magnetic field was registered in the stations located at the highest latitude part of the IMAGE network, at $\sim$ 19:50-20:00 MLT (Fig. 1b). Thus, after $\sim 16: 30$ UT, the substorm developed at high latitudes in the evening sector. The disturbance ended at $\sim 18: 00 \mathrm{UT}$; this is also confirmed by the AE-index obtained from WDC-C2 in Kyoto (http://swdcdb.kugi.kyoto-u.ac.jp:80/aedir/ae1/quick.html).

\section{Interball-1 data}

During the substorm, Interball-1 was located most of the time in the plasma sheet. According to the magnetic field model of Tsyganenko (T89), its ionospheric footprint was within $\mathrm{MLT}=21.3-21.9 \mathrm{~h}$ and $\mathrm{CGML}=70.1-72.4^{\circ}\left(\right.$ for a $K_{p}$ 


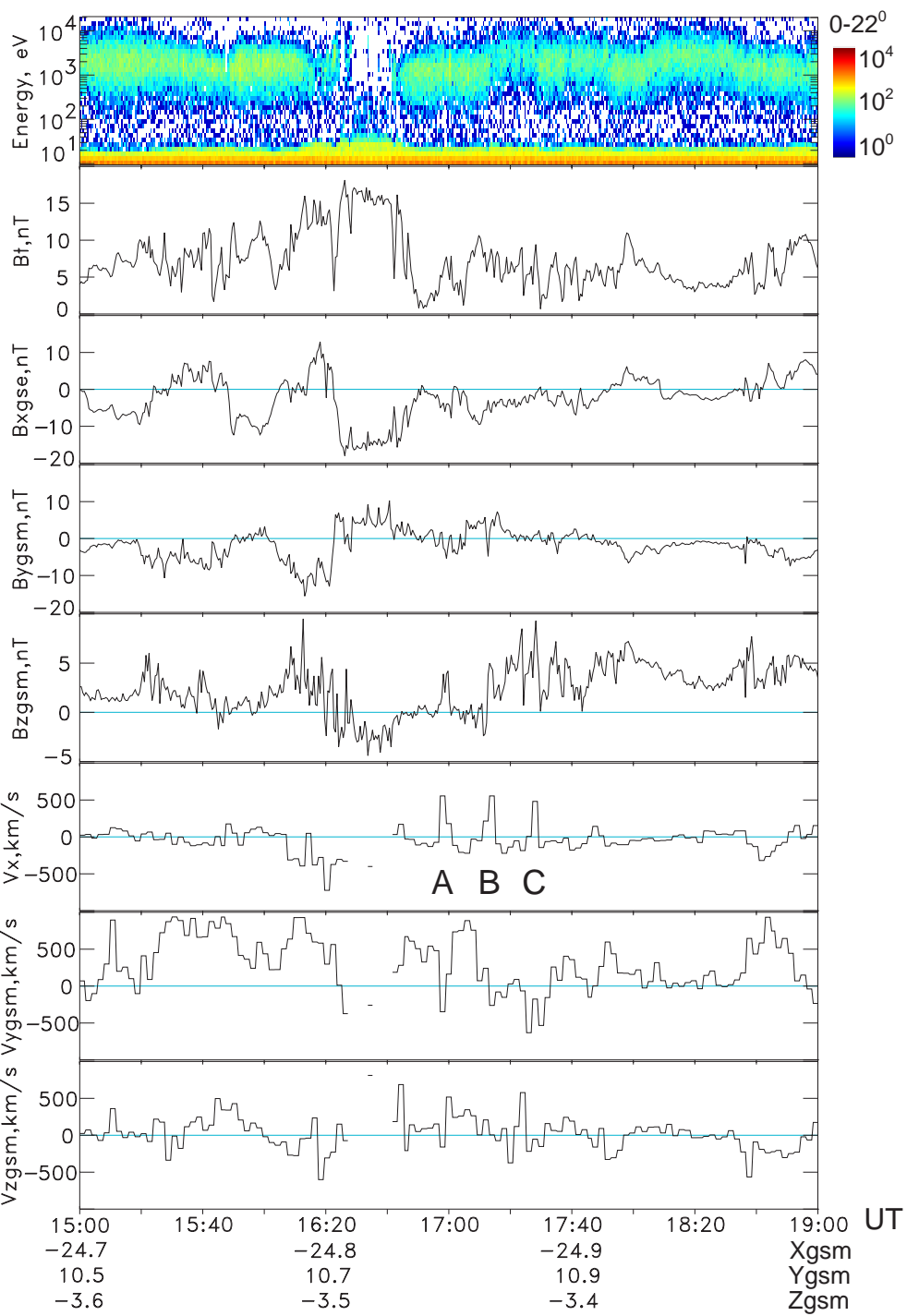

Fig. 2. Interball-1 data for the time interval 15:00-19:00 UT. From top to bottom: energy-time spectrogram of the tailward directed electrons (energy fluxes are color-coded), magnetic field magnitude, magnetic field and plasma velocity components in the GSM system. Labels A, B, and C indicate bursty bulk flow (BBF) events discussed in the text. parameter of 7 and 1, respectively). Figure 2 presents a summary of the Interball-1 observations: energy-time spectrogram for tailward directed electrons; magnetic field magnitude $\boldsymbol{B} ;$ magnetic field components $B_{X}, B_{Y}$, and $B_{Z}$; plasma velocity components $V_{X}, V_{Y}$, and $V_{Z}$.

Plasma data exhibits an unusual feature during the event: a large flow directed duskward (up to $1000 \mathrm{~km} / \mathrm{s}$ ). A divergence of the earthward plasma convection toward flanks of the magnetosphere was already reported (e.g. Sergeev and Lennartson, 1988). The observation of duskward flow is likely to be related to the location of the spacecraft in the dusk magnetotail. However, the origin of such a large $V_{Y}$ is unclear.

Another remarkable feature is the wavy structure of the magnetic field and plasma density seen during some substorm activations. Figure 3a shows the Interball-1 data for the interval 16:11-16:15 UT. Clear, quasi-sinusoidal oscillations (with a period varying from 10 to $25 \mathrm{~s}$ ) are seen in the magnetic field components and modulus. The signal is el- liptically polarized. The field enhancements and decreases correlate with decreases and increases in the electron density, respectively. Minimum variance analysis shows that the wave normal vector lies approximately in the $X-Y$ plane $(X=-0.77, Y=+0.63, Z=+0.09)$. One can interpret the waves as signaling current sheet filamentary structures moving across the satellite location.

At 16:08 UT (when active auroras approached the longitude of the spacecraft footprint), Interball-1 started to register tailward plasma flows (Figs. 2 and 4). These bursty tailward flows were detected until 16:24 UT when the spacecraft entered the tail lobe. Afterwards and until 16:44 UT, the satellite was located in the southern tail lobe; therefore, there was no possibility to measure the plasma sheet flow direction. Following the plasma sheet expansion, at least three fast earthward plasma flows were detected. The flows were short-lived, and every one of them corresponded to an impulsive enhancement of the $B_{Z}$ component of the magnetic field (dipolarization). Thus, the flows exhibit the typical sig- 

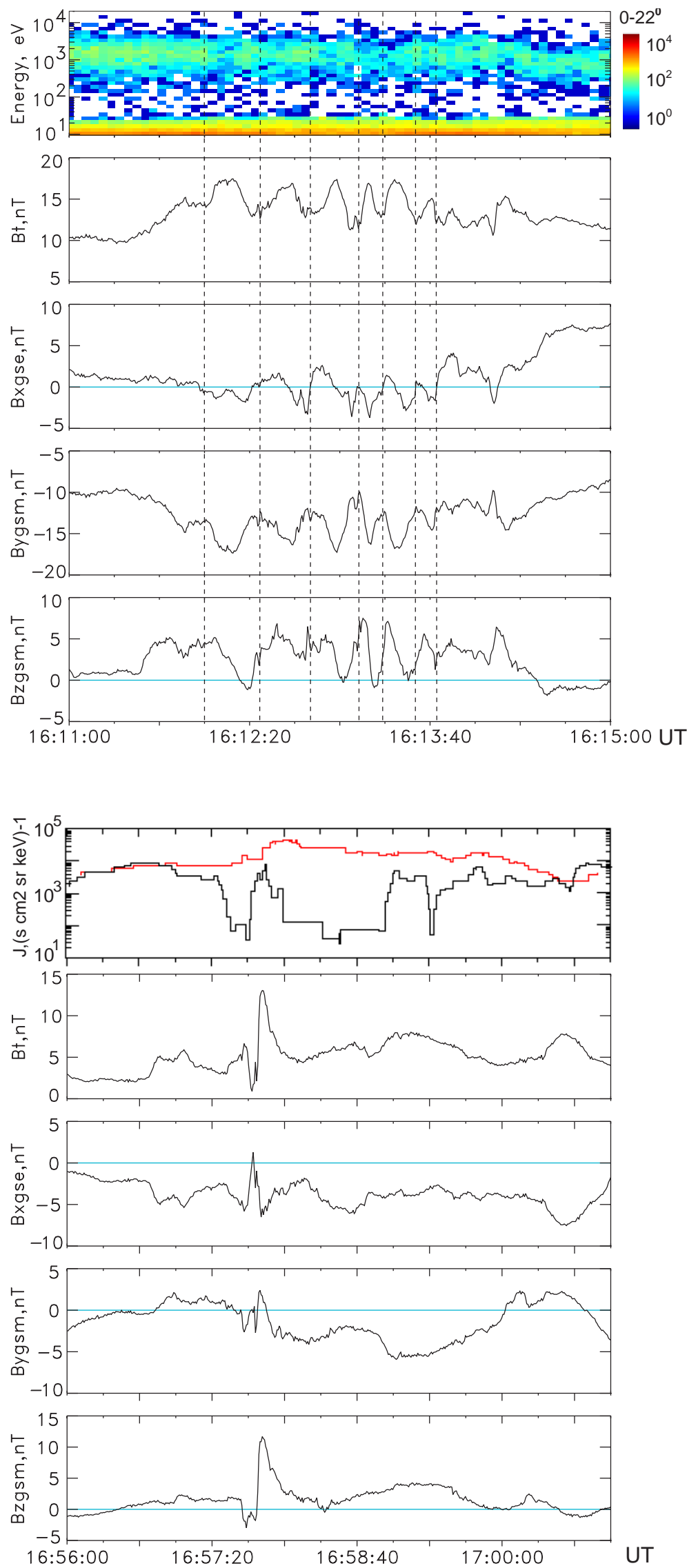

UT
Fig. 3a. Sequence of 7 structures in the magnetic field and electron fluxes between 16:11 and 16:15 UT. From top to bottom: the electron energy-time spectrogram, and $\boldsymbol{B}, B_{X}, B_{Y}, B_{Z}$ in GSM coordinate system. Vertical dashed lines separate the observed structures.
Fig. 3b. Energetic ions and magnetic field variations during the bursty bulk flow event detected between 16:56:00 and 17:00:40 UT (event A in Fig. 2). From top to bottom: ion fluxes in the energy range $21-28 \mathrm{keV}$ (the red curve is for ions streaming tailward, the black one for ions streaming approximately earthward), magnetic field magnitude and components. 

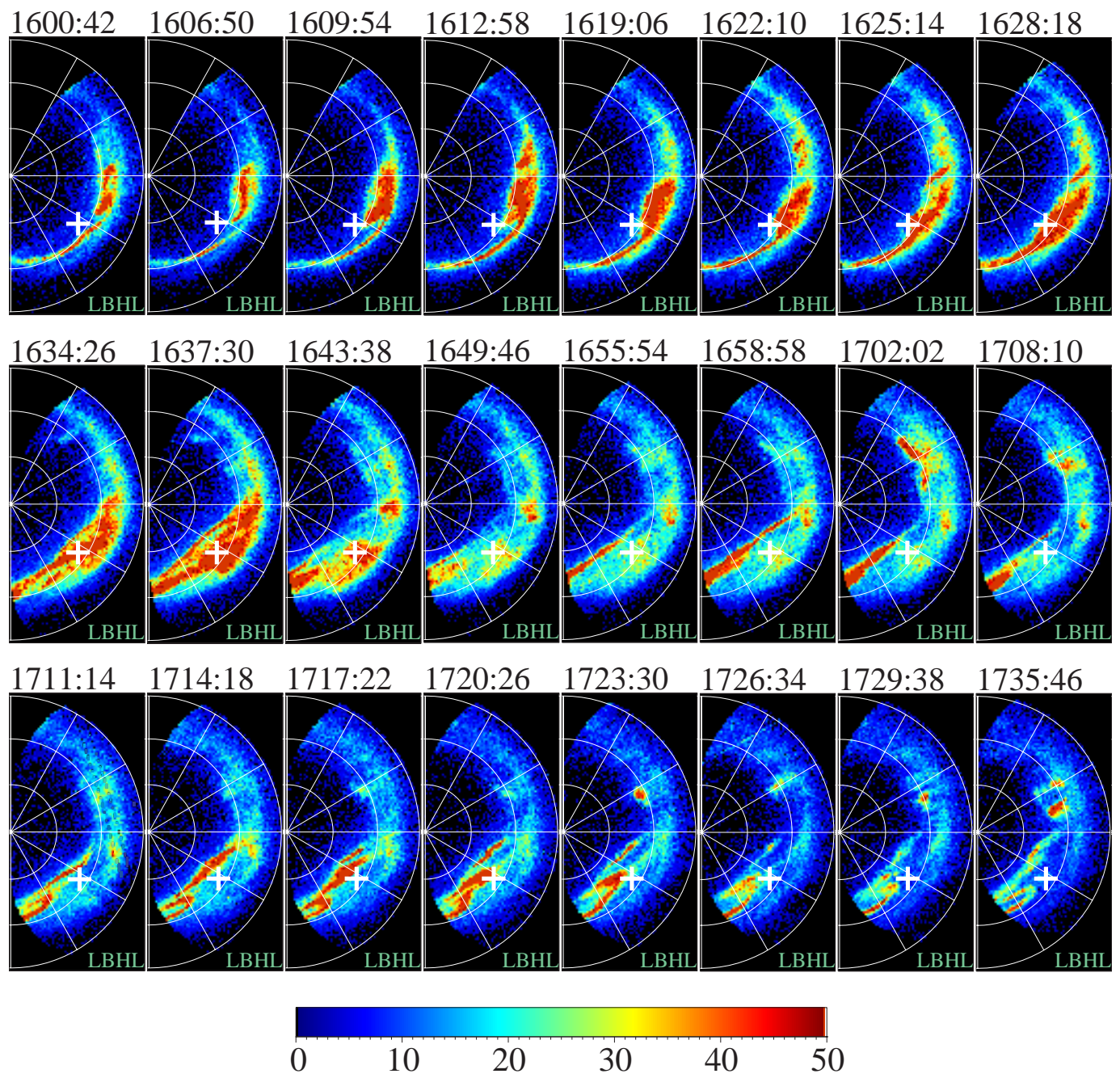

Fig. 4. A sequence of Polar UVI images recorded on 16 December 1998 between 16:00:42 and 17:35:46 UT. Only every third image is displayed. The projection of the Interball-1 satellite at ionospheric altitude as computed from T89 is indicated by a white cross in each panel.

natures of BBFs (Angelopoulos et al., 1992). The magnetic structure of the BBF registered at $\sim 16: 58 \mathrm{UT}$ (event A) and the associated anisotropy in energetic (21-28 keV) ion fluxes streaming earthward and tailward are illustrated in Fig. $3 \mathrm{~b}$.

\section{Relation between tail dynamics and auroral activa- tions}

Figure 4 presents a sequence of Polar UVI images in a CGLMLT frame. The Sun is on the right side of this figure. The first image at 16:00:42 UT is taken soon after the substorm onset in the midnight sector. At that time, the Interball1 ionospheric footprint was located poleward and slightly westward of the active aurora. Interball-1 detected tailward flowing plasma from 16:02 to 16:24 UT (lobe exit); during this time interval active auroras were located southward of the satellite footprint. The image at 16:12:58 UT corresponds to the time when the wave structure was detected in the plasma sheet. After 16:22-16:25 UT, the main auroral ac- tivity shifted to the evening sector, and reached the meridian of the spacecraft. This is also confirmed by the magnetometer data from the IMAGE network which started to register a westward electrojet at $\sim 16: 25$ UT, i.e. at MLT $=19.5$ (Fig. 1b). As described in the preceding section, the satellite was out of the plasma sheet from 16:24 to 16:44 UT. The plasma sheet thinning (16:22 UT) coincided with a new activation of auroras, which first occupied the footprint of Interball-1 and then moved further poleward. After the plasma sheet expansion, BBF-like earthward plasma flows started around 16:58 UT (event A in Fig. 2, see also Fig. 3b). In Fig. 4, this time corresponds to the brightening of an auroral arc located well poleward of the Interball-1 footprint (at $\mathrm{CGL} \approx 75^{\circ}$ ). The arc was forming the poleward edge of the auroral display. A new auroral activation occurred poleward of the spacecraft footprint at 17:14:18 UT. Again, it corresponded to a fast flow burst seen in the Interball-1 data (event B in Fig. 2). The last, very short flow burst ( 17:30 UT, event C) can also be associated with the reappearance of an arc poleward the Interball-1 footprint, although this arc was 
not as bright as the previous one.

\section{Conclusion and discussion}

The main conclusion of this study is that the direction (tailward or earthward) of impulsive plasma flows detected in the mid-tail correlates with the location of aurora forming the auroral bulge relative to the satellite footprint. During substorm expansion, while aurora are located equatorward of the satellite (stage 1), the plasma flow is directed tailward. Activations of auroras poleward of the satellite footprint (stage 2) are associated with earthward flow. According to the NENL model of substorm, it means that the reconnection site (or flow reversal region) should be located earthward of the satellite during stage 1 and tailward of it during stage 2. This is in agreement with the concept that the NENL maps into the poleward edge of the auroral bulge (e.g. Pudovkin et al., 1991).

This also agrees with the result of Fairfield et al. (1999) who found that earthward flow at distances $<15 R_{E}$ appears when auroral activation occupies the location of the satellite footprint and with the multi-point measurements performed by Petrukovich et al. (1998), where two satellites (Interball1 and Geotail) situated near the neutral sheet at $X=-12$ and $-28 R_{E}$ (and having close footprints in the ionosphere) observed earthward and tailward flows, respectively, during an auroral breakup occurring near the spacecraft footprints.

During substorms, flow reversals have been observed to propagate up to $X=-60 R_{E}$ simultaneously with steplike poleward propagation of the westward electrojet; at the same time, dipolarization has been observed at $X=-30 R_{E}$ (Angelopolous et al., 1996). Dipolarization is considered as a signature of the cross-tail current disruption, and the electrojet constitutes the closure of the disrupted current in the ionosphere. Keeping in mind that a westward electrojet typically develops inside the auroral bulge where conductivity is increased, the result of Angelopolous et al. (1996) does not contradict our conclusion.

We have shown that earthward flow bursts in the mid-tail correspond to auroral activations at the poleward edge of an expanded auroral bulge. The observed flow bursts have the characteristics of BBFs described by Angelopolous et al. (1992). Thus, we may conclude that at least some BBFs result from reconnection occurring during the late stage of substorm in the same longitudinal sector, but tailward of the observing spacecraft. This result is in agreement with the work of Nakamura et al. (2000), who evidenced the relationship between BBFs and auroral activations poleward of the spacecraft footprint, and also with the results of Lyons et al. (1998) and Zesta et al. (2000), who concluded that auroral intensifications at the poleward edge of the auroral oval are closely related to BBFs.

Furthermore, the Interball-1 measurements in the mid-tail evidence the turbulent nature of the plasma sheet during substorm activations. A detailed study of this turbulent behavior will be studied in forthcoming papers.
Acknowledgements. We are grateful to Dr. O. Troshichev for providing magnetograms from several Siberian stations and to Drs. S. Solovyev, V. Parkhomov, and J. Manninen for information on geomagnetic pulsations. Data of the IMAGE network were retrieved from http://www.geo.fmi.fi/image. We thank Prof. G. K. Parks for the permission to use data from the Polar UVI instrument. The work was partly supported by INTAS grant 99-0078.

Topical Editor G. Chanteur thanks two referees for their help in evaluating this paper.

\section{References}

Angelopoulos, V., Baumjohann, W., Kennel, C. F., et al.: Bursty bulk flows in the inner central plasma sheet., J. Geophys. Res., 97, 4027, 1992.

Angelopoulos, V., Mitchell, D. G., McEntire, R. W., et al.: Tailward progression of magnetotail acceleration centers: Relationship to substorm current wedge, J. Geophys. Res., 101, 24 599, 1996.

Baker, D. N., Pulkkinen, T. I., Angelopoulos, V., Baumjohann, W., and McPherron, R. L.: Neutral line model of substorms: Past results and present view, J. Geophys. Res., 101, 12 975, 1996.

Fairfield, D. H., Mukai, T., Brittnacher, M., et al.: Earthward flow bursts in the inner magnetotail and their relation to auroral brightenings, AKR intensifications, geosynchronous particle injections and magnetic activity, J. Geophys. Res., 104, 355, 1999.

Henderson, M. G., Reeves, G. D., and Murphree, J. S.: The activation of the dusk-side and the formation of north-south aligned structures during substorms, in Proc. Second International Conference on Substorms (ICS-2), (Eds) Kan, J. R., Craven, J. D., and Akasofu, S.-I., Geophysical Institure, University of Alaska Fairbanks, p. 37, 1994.

Henderson, M. G., Reeves, G. D., and Murphree, J. S.: Are northsouth structures an ionospheric manifestation of bursty bulk flows?, Geophys. Res. Lett., 25, 3737, 1998.

Hones, Jr., E. W.: Transient phenomena in the magnetotail and their relation to substorms, Space Sci. Rev., 16, 617, 1979.

Hones, Jr., E. W.: Poleward leaping aurora, the substorm expansive and recovery phases and the recovery of the plasma sheet, Substorm 1, Eur. Space Agency, Spec. Publ., ESA SP-335, p. 477, 1992.

Ieda, A., Fairfield, D. H., Mukai, T., et al.: Plasmoid ejection and auroral brightenings, J. Geophys. Res., 106, 3845, 2001.

Lyons, L. G., et al.: Near Earth plasma sheet penetration and geomagnetic disturbances, In: New Perspectives of the Earth' Magnetotail, (Eds) Nishida, A., Cowley, S. W. H., and Baker, D. N., AGU, Washington, D. C., p. 241, 1998.

Nagai, T., et al.: Structure and dynamics of magnetic reconnection for substorm onset with Geotail observations, J. Geophys. Res., 103, 4419, 1998.

Nakamura, R., Oguti, T., Yamamoto, T., and Kokubun, S.: Equatorward and poleward expansion of the auroras during auroral substorm, J. Geophys. Res., 98, 5741, 1993.

Nakamura, R., Baumjohann, W., Sergeev, V. A., et al.: Fast flow bursts and auroral activations, Proc. of the Fifth International Conference on Substorms, (Ed) Wilson, A., ESA Publications Division, The Netherlands, p. 319, 2000.

Petrukovich, A. A., Sergeev, V. A., Zeleniy, L. M., et al.: Two spacecraft observations of a reconnection pulse during an auroral breakup, J. Geophys. Res., 103, 47, 1998.

Pudovkin, M. I., Semenov, V. S., Starkov, G. V., and Kornilova, T. A.: On separation of the potential and vortex parts of the magne- 
totail electric field, Planet. Space Sci., 39, 563, 1991.

Sergeev, V. A. and Lennartsson, W.: Plasma sheet at $X=20 R_{E}$ during steady magnetospheric convection, Planet. Space Sci., 34, 353, 1988.

Sergeev, V. A., et al.: Development of auroral streamers in association with impulsive injections to the inner magnetotail, Geophys. Res. Lett., 26, 417, 1999.

Sergeev V. A., J Sauvaud, .-A., Popescu, D., et al.: Multiplespacecraft observation of a narrow transient plasma jet in the
Earth's plasma sheet, Geophys. Res. Lett., 27, 851, 2000.

Solovyev, S. I., Baishev, D. G., Barkova, E. S., Engebretson, M. J., Posch, J. L., Yumoto, K., and Pilipenko, V. A.: Structure of disturbances in the dayside and nightside ionosphere during periods of negative interplanetary magnetic field $B_{Z}$, J. Geophys. Res. 104, 28 019, 1999.

Zesta, E., Lyons, L. R., and Donovan, E.: The auroral signature of Earthward flow bursts observed in the magnetotail, Geophys. Res. Lett., 27, 3241, 2000. 